\title{
Acidification of musts in warm regions with tartaric acid and calcium sulfate at industrial scale
}

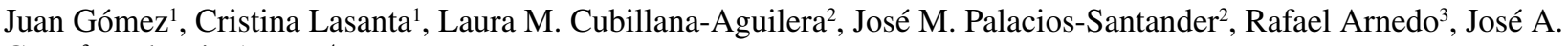 \\ Casas $^{3}$, and Luis Arroyo ${ }^{4}$
${ }^{1}$ Departamento de Ingeniería Química y Tecnología de Alimentos, Universidad de Cádiz, Campus Universitario de Puerto Real, C/República Saharaui s/n, 11510, Puerto Real, Cádiz, Spain
${ }^{2}$ Departamento de Química Analítica, Facultad de Ciencias, Universidad de Cádiz, Campus Universitario de Puerto Real, C/República Saharaui s/n, 11510, Puerto Real, Cádiz, Spain
${ }^{3}$ Bodegas González-Byass, C/Manuel María González, 12, 11403 Jerez, Spain
${ }^{4}$ Bodegas Garvey, Complejo Bellavista, Carretera Ronda Circunvalación, s/n, 11407 Jerez, Spain

\begin{abstract}
Acidification of musts is necessary in warm areas where high temperatures during ripening accelerate breathing combustion of tartaric acid and, in particular, malic acid in the berries. L(+) tartaric acid, L(-) or D,L malic acid and lactic acids are the only chemical acidifiers authorized by the OIV and European Community regulations. The use of calcium sulfate (gypsum: $\mathrm{CaSO}_{4} \cdot 2 \mathrm{H}_{2} \mathrm{O}$ ) is also authorized in the European Community as a complementary acidifier in generous and generous liquor wines from Spain (a practice known as plastering), provided that the residual sulfate content in the wine does not exceed $2.5 \mathrm{~g} / \mathrm{L}$ expressed as potassium sulfate. However, this practice is not yet approved by OIV. To predict the effect on $\mathrm{pH}$ of different acidifiers, several chemical modeling approaches have been described in the literature, in particular a simplified model where the acidity of wine is considered to be due to a monoprotic acid. The aim of this work is to verify this model at pilot and industrial scale in the acidification of musts with tartaric and calcium sulfate, added either individually and in combination, using doses up to $3 \mathrm{~g} / \mathrm{L}$ and to study the modifications that these practices produce on the compositions of the resulting wines. This work supplies useful information to study this practice in OIV in order to consider its approval.
\end{abstract}

\section{Introduction}

The acidification of musts has the objective of reducing their $\mathrm{pH}$ to suitable values in order to inhibit bacterial activity, stabilize the color and improve the sensorial characteristics of the resulting wines. The intensity of the acidic taste of wines is directly related to the $\mathrm{pH}$ and its length with the buffering power [1]. Acidification of musts is necessary in warm areas where high temperatures during ripening accelerate breathing combustion of tartaric acid and, in particular, malic acid in the berries [2]. L(+)-tartaric acid has traditionally been the only acidification agent used to date but the latest regulations of the European Union also authorize the use of L-malic acid, D,L-malic acid and lactic acid $[3,4]$. The maximum authorized doses are $1.5 \mathrm{~g} / \mathrm{L}$ in grape juice and $2.5 \mathrm{~g} / \mathrm{L}$ in wine, expressed as tartaric acid. The use of calcium sulfate (gypsum: $\mathrm{CaSO}_{4} \cdot 2 \mathrm{H}_{2} \mathrm{O}$ ) is also authorized as a complementary acidifier in generous and generous liquor wines from Spain (a practice known as plastering) provided that the residual sulfate content in the wine does not exceed $2.5 \mathrm{~g} / \mathrm{L}$ expressed as potassium sulfate. Calcium sulfate is also authorized in the United States for the production of wines aged under yeast veil but residual sulfate cannot exceed $2 \mathrm{~g} / \mathrm{L}$ [5]. Plastering is a practice that has its roots in history [6] and this approach has traditionally been used in Sherry [7-9] and Port winemaking [10]. More recently,
Gómez et al. [11] recommended a combined acidification with $2 \mathrm{~g} / \mathrm{L}$ of gypsum and sufficient tartaric acid to achieve a $\mathrm{pH}$ of 3.25. In this way, the necessary dose of tartaric acid does not exceed $1.5 \mathrm{~g} / \mathrm{L}$, the maximum authorized level, and the final concentration of sulfates is lower than $2.5 \mathrm{~g} / \mathrm{L}$. Moreover, Casas [12] proposed a semiempirical method to calculate the doses of gypsum and tartaric acid required to reduce the $\mathrm{pH}$ of the musts to 3.40.

Several chemical modeling approaches have been described in the literature with the aim of predicting the effect of acidification on $\mathrm{pH}$ and the general acid-base properties and ionic strength in white and red wines. Boulton [13] proposed a simple model in which the $\mathrm{pH}$ is expressed as a function of the titratable acidity, the potassium and sodium contents and the tartrate to malate ratio. Moreno and Peinado [14] updated and improved the model proposed by Usseglio-Tomasset [15] and developed a model simple and easy to apply. In this model the acidity of wine is considered to be due to a monoprotic acid. The dissociation of the acid can be represented as follows:

$$
H A \leftrightarrow A^{-}+H^{+}
$$

The acidity constant would be

$$
K_{V}=\frac{\left[A^{-}\right]\left[H^{+}\right]}{H A}
$$


and

$$
p K_{V}=p H-\log \frac{\left[A^{-}\right]}{[H A]}
$$

which can be written as

$$
p K_{V}=p H-\log \frac{[A A]}{[T A]}
$$

where TA is total acidity and AA is ash alkalinity.

The buffering power of the must depends on the concentration of the various ionic forms of tartaric acid in accordance with the following expression:

$$
\pi=\text { Buffering Power }=\frac{d A c}{d p H}=2.303 \frac{[H A]\left[A^{-}\right]}{[H A]+\left[A^{-}\right]}
$$

which can be simplified as

$$
\pi=\text { Buffering Power }=\frac{d A c}{d p H}=2.303 \frac{[T A][A A]}{[T A]+[A A]}
$$

Buffering power can be easily determined in the laboratory and allows the calculation of AA:

$$
A A=\frac{\pi \times T A}{2.303 \times T A-\pi}
$$

All of these approximations can be applied since the variation of $\mathrm{pH}$ is considered to be infinitesimal.

The effect on $\mathrm{pH}$ of adding $X$ meq $/ \mathrm{L}$ of tartaric acid can be predicted by considering that

$$
T A_{f}=T A_{i}+2 X
$$

and

$$
A A_{f}=A A_{i}
$$

where the subscripts " $i$ " and " $f$ " denote initial and final, respectively.

In this way, the final $\mathrm{pH}$ value can be calculated as:

$$
p H_{f}=p K_{V}+\log \frac{A A_{f}}{T A_{f}}=p K_{V}+\log \frac{A A_{i}}{T A_{i}+2 X}
$$

After the addition of tartaric acid a precipitation of $\mathrm{X}$ meq/L of potassium bitartrate will occur and AA and TA will be modified as follows:

$$
A A_{f}=A A_{i}-X
$$

and

$$
T A_{f}=T A_{i}+2 X-X=T A_{i}+X .
$$

And the final $\mathrm{pH}$ would be calculated as:

$$
p H=p K_{V}+\log \frac{A A_{f}}{T A_{f}}=p K_{V}+\log \frac{A A_{i}-X}{T A_{i}+X}
$$

In this model it is considered that the medium is saturated in tartrate and, as a consequence, the addition of tartaric acid as an acidifying agent will introduce the common ion $\mathrm{HT}^{-}$and this will precipitate naturally or during cold stabilization as potassium bitartrate. In this way, one can consider that all of the $\mathrm{HT}^{-}$added will precipitate as potassium bitartrate and this does not contribute to the titratable acidity [14].

The effect of $\mathrm{CaSO}_{4}$ in grape must is based on the displacement of the ionic equilibrium produced by the $\mathrm{Ca}^{2+}$ ion. The equilibria of two salts with limited solubility are involved in this case, namely $\mathrm{CaSO}_{4}$ $\left(K_{\mathrm{SP}}=6.1 \times 10^{-5}\right)$ and calcium tartrate $\left[\mathrm{Ca}\left(\mathrm{C}_{4} \mathrm{H}_{4} \mathrm{O}_{6}\right)^{4}\right.$, hereafter CaT] $\left(K_{\mathrm{SP}}=7.7 \times 10^{-7}\right) . \mathrm{CaSO}_{4}$ dissolves up to the solubility products of the $\mathrm{CaSO}_{4}$ and $\mathrm{CaT}$. As the latter species is much less soluble than the former, the precipitation of $\mathrm{CaT}$ occurs. However, on decreasing the concentration of one of the ionic forms of tartaric acid (hereafter $\mathrm{H}_{2} \mathrm{~T}$ ), a redistribution of the other occurs and, in accordance with the dissociation constants of this acid $\left(K_{1}=1.04 \times 10^{-3} ; K_{2}=4.55 \times 10^{-5}\right)$ and to replace the removed tartrate ion (hereafter $\mathrm{T}^{2-}$ ), a proportion of the bitartrate ion (thereafter $\mathrm{HT}^{-}$) is dissociated and this in turn is replaced by another tartrate from the dissociation of $\mathrm{H}_{2} \mathrm{~T}$. The different ionic reactions considered are as follows:

$$
\begin{gathered}
T^{2-}+\mathrm{Ca}^{2+} \leftrightarrow C a T \downarrow \\
H T^{-} \leftrightarrow T^{2-}+H^{+} \\
H_{2} T \leftrightarrow H T^{-}+H^{+}
\end{gathered}
$$

which gives rise to the following global reaction:

$$
\mathrm{Ca}^{2+}+\mathrm{H}_{2} \mathrm{~T} \rightarrow \mathrm{CaT} \downarrow+2 \mathrm{H}^{+}
$$

The release of these two protons leads to a decrease in the $\mathrm{pH}$ of the must.

The addition of $Y$ meq/ $/ \mathrm{L}$ of $\mathrm{CaSO}_{4}$ removes $Y$ meq/L of tartrate and AA and TA will also decrease to the same extent. Therefore,

$$
\begin{gathered}
A A_{f}=A A_{i}-Y \\
T A_{f}=T A_{i}-Y
\end{gathered}
$$

The buffering power will be affected differently depending on whether the acidification is carried out with gypsum or tartaric acid. The increase in the fraction [HA] on adding tartaric acid should affect the numerator rather than the denominator in Eq. (6), thus causing an increase in the buffering power. Similarly, the decrease of $\left[\mathrm{A}^{-}\right]$caused by the addition of gypsum will cause a decrease in the buffering power.

The aim of the work described here was to expand on the procedure described by Gomez [11], for the acidification of musts with gypsum and tartaric acid, added either individually and in combination, using doses up to $3 \mathrm{~g} / \mathrm{L}$ and to study the modifications that these practices produce on the compositions of the resulting wines. At the same time, chemical modeling of the acid-base and precipitation equilibria was carried out to calculate $\mathrm{pH}$ values and compare them with the experimental ones in order to predict the final $\mathrm{pH}$ achieved with specific doses of tartaric acid and gypsum. Through these studies the traditional practice of plastering will be explained and evidence will be provided to support this process. 


\begin{tabular}{|c|c|c|c|c|c|c|c|c|c|c|c|c|c|}
\hline \multicolumn{2}{|c|}{ 幽 } & $\stackrel{0}{0}$ & $\stackrel{\bullet}{-}$ & $\underset{\infty}{-\infty}$ & $\begin{array}{l}\infty \\
0 \\
0 \\
0\end{array}$ & $\begin{array}{l}\infty \\
\stackrel{0}{0} \\
0\end{array}$ & $\begin{array}{l}\text { D. } \\
\dot{0}\end{array}$ & $\begin{array}{l} \pm \\
⿱ 亠 䒑 \\
0\end{array}$ & ஸे. & $\stackrel{\Im}{\circ}$ & \begin{tabular}{l|l}
0 & \multicolumn{2}{c}{} \\
0 & 0
\end{tabular} & \begin{tabular}{lll}
$c$ \\
$\dot{0}$ & \multirow{2}{0}{}
\end{tabular} & \\
\hline \multicolumn{2}{|c|}{ 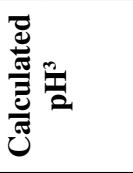 } & $\mid \begin{array}{l}\hat{r} \\
\dot{m}\end{array}$ & 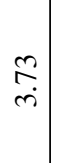 & ஸे & $\stackrel{⿱ 宀}{\dot{m}}$ & $\stackrel{n}{n}$ & $\underset{\dot{m}}{\dot{m}}$ & $\begin{array}{c}\vec{f} \\
\dot{c}\end{array}$ & $\begin{array}{l}\grave{n} \\
\end{array}$ & \begin{tabular}{lll}
$\stackrel{a}{0}$ & \multicolumn{1}{c}{} \\
$\dot{m}$
\end{tabular} & 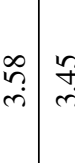 & 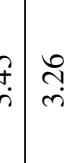 & \\
\hline \multicolumn{2}{|c|}{$\vec{a}$} & $\mid \begin{array}{l}\hat{\sigma} \\
\dot{+}\end{array}$ & $\begin{array}{l}\overrightarrow{\dot{f}} \\
\dot{+}\end{array}$ & $\vec{\sigma}$ & $\begin{array}{c}\mathscr{D} \\
\infty \\
\dot{\infty}\end{array}$ & $\tilde{\sigma}$ & $\begin{array}{c}\infty \\
\dot{\infty} \\
\dot{n}\end{array}$ & $\begin{array}{l}\triangleright \\
\infty \\
\dot{\infty}\end{array}$ & $\stackrel{\infty}{\stackrel{\infty}{\dot{m}}}$ &  & \begin{tabular}{l|l}
$\delta$ & $n$ \\
$\dot{+}$ & $\tilde{z}$
\end{tabular} & 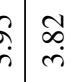 & \\
\hline \multicolumn{2}{|c|}{ 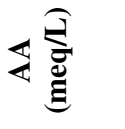 } & 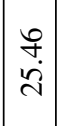 & $\begin{array}{l}8 \\
\grave{i} \\
\text { i }\end{array}$ & 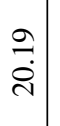 & $\begin{array}{l}\stackrel{?}{0} \\
\infty \\
\infty\end{array}$ & $\begin{array}{l}m \\
\stackrel{m}{\Delta}\end{array}$ & $\underset{\substack{q \\
\dot{v}}}{ }$ & $\stackrel{5}{\circ}$ & $\begin{array}{l}\stackrel{P}{P} \\
\infty \\
\infty\end{array}$ & 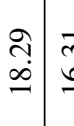 & \begin{tabular}{c|c}
$\bar{m}$ & $\bar{J}$ \\
$\dot{\sigma}$ & $\exists$
\end{tabular} & 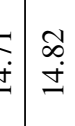 & \\
\hline \multicolumn{2}{|c|}{ 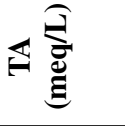 } & $\mid \begin{array}{c}\hat{\sigma} \\
\dot{\rho} \\
\dot{\sigma}\end{array}$ & $\begin{array}{c}8 \\
\stackrel{0}{+} \\
\dot{q}\end{array}$ & $\begin{array}{c}\tilde{\sigma} \\
\dot{\sigma} \\
\dot{\sigma}\end{array} \mid$ & $\begin{array}{c}8 \\
\dot{0} \\
\dot{\phi} \\
\end{array}$ & \begin{tabular}{c|}
$c$ \\
$\dot{q}$ \\
$\dot{q}$
\end{tabular} & $\begin{array}{l}\tilde{\partial} \\
\hat{\delta} \\
\text { in }\end{array}$ & $\begin{array}{c}m \\
\stackrel{\infty}{n} \\
i n\end{array}$ & $\begin{array}{l}\stackrel{n}{f} \\
\stackrel{n}{n}\end{array}$ & $\begin{array}{c}\stackrel{f}{f} \\
\stackrel{f}{f}\end{array}$ &  & 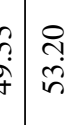 & \\
\hline \multicolumn{2}{|c|}{ 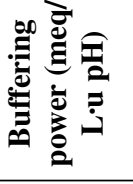 } & $\mid \begin{array}{c}n \\
\infty \\
\infty \\
m\end{array}$ & $\begin{array}{l}\stackrel{+}{+} \\
\dot{\vec{f}}\end{array}$ & $\begin{array}{l}\hat{\sigma} \\
\hat{\sim}\end{array}$ & $\begin{array}{l}\tilde{m} \\
\dot{m}\end{array}$ & 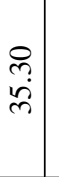 & $\begin{array}{l}\stackrel{P}{+} \\
\dot{f}\end{array}$ & $\begin{array}{l}\stackrel{\sim}{m} \\
\text { }\end{array}$ & $\begin{array}{l}\infty \\
\infty \\
i \\
m\end{array}$ & $\begin{array}{c}q \\
+ \\
\dot{m}\end{array}$ & 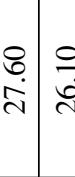 & 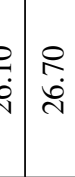 & \\
\hline \multicolumn{2}{|c|}{ 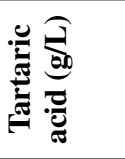 } & $\mid \begin{array}{c}n \\
\infty \\
0 \\
\sigma \\
\sigma\end{array}$ & $\begin{array}{l}n \\
\underline{b} \\
\dot{n} \\
\end{array}$ & $\underset{+}{\curvearrowright}$ & $\begin{array}{l}\underset{+}{+} \\
\dot{+}\end{array}$ & $\hat{\dot{m}}$ & $\begin{array}{l}v \\
\infty \\
\infty \\
r\end{array} \mid$ & $\begin{array}{l}\infty \\
\stackrel{+}{+}\end{array}$ & $\begin{array}{l}\stackrel{g}{o} \\
\dot{+}\end{array}$ & $\stackrel{\infty}{\stackrel{\infty}{\rightarrow}}$ & \begin{tabular}{l|lll}
$\infty$ & $\infty$ \\
$-\infty$ & $\infty$ \\
- & 0
\end{tabular} & 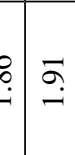 & \\
\hline \multicolumn{2}{|c|}{ 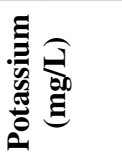 } & \begin{tabular}{l|}
$\infty$ \\
$\stackrel{2}{\vec{\nu}}$
\end{tabular} & $\begin{array}{l}\infty \\
\stackrel{\sim}{二}\end{array}$ & $\begin{array}{l}\infty \\
\stackrel{\sim}{\sim}\end{array}$ & ڤ્તે & 字 & $\begin{array}{l}\hat{0} \\
:\end{array}$ & $\begin{array}{l}\stackrel{\infty}{\infty} \\
-\infty\end{array}$ & § & ๙ू & 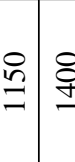 & $\begin{array}{ll}b \\
\vdots \\
q\end{array}$ & \\
\hline \multicolumn{2}{|c|}{ 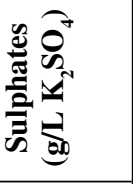 } & $\exists$ & $\exists$ & $\underset{z}{=}$ & $\tilde{z}$ & ñ & 䒠 & $\begin{array}{l}\stackrel{D}{b} \\
i\end{array}$ & ڤ్ & \begin{tabular}{l|l}
0 \\
\hdashline \\
\hdashline & 4
\end{tabular} & 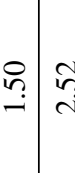 & 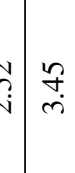 & \\
\hline \multicolumn{2}{|c|}{ 竞 } & $\stackrel{\cong}{\bumpeq}$ & 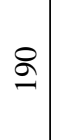 & $\underset{\sim}{~}$ & 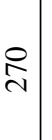 & o & 6 & $\underset{1}{8}$ & తి & o & 62 & 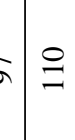 & 9 \\
\hline \multicolumn{2}{|c|}{ 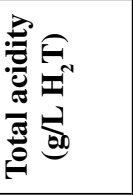 } & \begin{tabular}{|c|}
$\vec{b}$ \\
$\dot{r}$
\end{tabular} & $\begin{array}{l}\stackrel{\leftrightarrow}{\leftrightarrow} \\
\dot{r}\end{array}$ & $\begin{array}{c}\hat{6} \\
\dot{r}\end{array} \mid$ & $\begin{array}{l}\stackrel{8}{0} \\
\dot{r}\end{array}$ & $\underset{\dot{r}}{\stackrel{+}{r}}$ & $\begin{array}{l}\widetilde{D} \\
\infty \\
\end{array}$ & 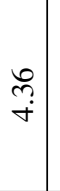 & $\stackrel{\substack{++}}{ }$ & 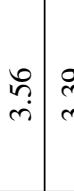 & 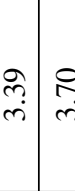 & $\begin{array}{lll}l & \sigma \\
\dot{r} & \sigma \\
\dot{m}\end{array}$ & 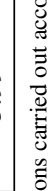 \\
\hline \multicolumn{2}{|l|}{ 몸 } & $\stackrel{\hat{r}}{\dot{r}}$ & $\begin{array}{l}\hat{\sigma} \\
\dot{r}\end{array}$ & $\stackrel{n}{m}$ & $\underset{\dot{f}}{\stackrel{f}{r}}$ & $\hat{n}$ & $\underset{\dot{q}}{\stackrel{g}{r}}$ & $\underset{m}{m}$ & $\begin{array}{l}\stackrel{\infty}{\sim} \\
\stackrel{n}{m}\end{array}$ & \begin{tabular}{c|c}
$\dot{b}$ & $a$ \\
$\dot{r}$ &
\end{tabular} & 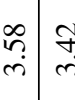 & 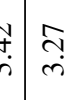 & $\frac{\tilde{J}}{\tilde{J}}$ \\
\hline \multirow{2}{*}{ 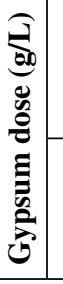 } & $\begin{array}{l}O^{+} \\
\text {đే } \\
\text { Uే }\end{array}$ & $\begin{array}{l}8 \\
0 \\
0\end{array}$ & $\stackrel{\imath}{\hat{0}}$ & $\stackrel{\infty}{\stackrel{\infty}{n}}$ & 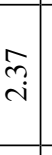 & $\begin{array}{l}8 \\
0\end{array}$ & $\stackrel{\overbrace{}}{0}$ & 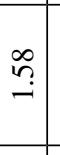 & $\hat{\tilde{i}}$ & $\begin{array}{ll}8 \\
0 \\
\end{array}$ & \begin{tabular}{l|l}
$\hat{\imath}$ & $\infty$ \\
0 &
\end{tabular} & 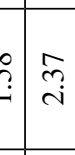 & 苋 \\
\hline &  & $\begin{array}{l}8 \\
0 \\
0\end{array}$ & $\underset{-}{8}$ & $\underset{i}{\stackrel{8}{ }}$ & $\begin{array}{l}8 \\
\dot{m}\end{array}$ & $\begin{array}{l}8 \\
0\end{array}$ & \&. & $\begin{array}{l}8 \\
i\end{array}$ & $\begin{array}{l}8 \\
\dot{m}\end{array}$ & 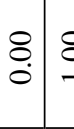 & \begin{tabular}{l|l}
8 \\
\end{tabular} & \begin{tabular}{c|c}
$B$ \\
$\dot{i}$ & 8 \\
\end{tabular} & \\
\hline \multicolumn{2}{|l|}{ 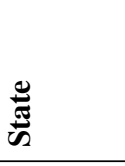 } & 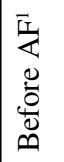 & & & & $\begin{array}{l}\frac{\pi}{4} \\
\frac{\vec{E}}{4}\end{array}$ & & & & 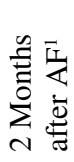 & & & \\
\hline
\end{tabular}




\section{Materials and methods}

\subsection{Description of the winemaking process}

The must for pilot scale tests was obtained in a previous harvest in a winery in the Jerez area (Southern Spain) from VitisVinifera $L$ cv. Palomino Fino grapes pressed at less than 1.0 bar and without sulphites.

The industrial scale tests were carried out in two different wineries in the harvest 2014. The musts were collected in 22,000 L stainless steel tanks, and acidified after the filling of the tank. Acidified musts were stirred with mechanicals systems and recirculation to ensure a good mixture of the acidifiers. Two tanks with the same acidifier were prepared every day. The musts were settled for a minimum of $18 \mathrm{~h}$, at controlled temperature, and 40,000 L of clear must were transferred to $50,000 \mathrm{~L}$ stainless steel tanks and fermented at $20^{\circ} \mathrm{C}$ with inoculums of selected ADY S. cerevisiae. It should be remarked that harvest 2014 has been very uncommon because the unusual mild summer produced musts with low $\mathrm{pH}$, what needed lower doses of acidifiers than usual.

\subsection{Sample preparation}

Samples before fermentation were taken of settled clear musts. Samples after fermentation were taken fifteen days after the end of alcoholic fermentation. An additional sampling was carried out 2 months after the end of fermentation. All samples were centrifuged and filtered through $8 \mu \mathrm{m}$ membrane before analysis and the fermented ones were also ultrasound degassed to remove $\mathrm{CO}_{2}$. All tests and analysis were performed in duplicate and average values are given in the tables.

\subsection{Analytical methods}

The $\mathrm{pH}$, total acidity, potassium, calcium and sulphates were analysed by the official European Union analysis methods [16]. Buffering power was determined by titration until $\mathrm{pH}=3$ with $0.1 \mathrm{~N}$ of $\mathrm{HCl}$. The results are expressed in $\mathrm{meq} / \mathrm{L} \mathrm{pH}$ unit. Tartaric acid was determined by colorimetric method [17].

\subsection{Equipment}

pH-meter: Metrohm 780 pH Meter. Atomic absorption spectrophotometer: Perkin-Elmer Model Analyst 100. Multiparametric: I.S.E. Group Miura One 15.

\subsection{Reagents}

All laboratory reagents were of analytical grade. The water for the preparation of solutions and controls was bi-distilled. Gypsum and tartaric acid were food quality. Gypsum and tartaric acid were added directly to the must and stirred until they were dissolved.

\subsection{Sensorial analysis}

Sensorial analysis of samples was made two months after fermentations and carried out by the tasters' panel of Jerez-Xérèz-Sherry Regulator Council, trained with ISO $8586: 2012$ criteria [18]. The tasters tried to find differences only in acidity among the samples and ordered them according to the intensity of the acid taste.

\subsection{Statistical treatment of data and modelling}

The nonparametric data were analyzed by studying the variance for unequal sample size, using the $\mathrm{H}$ Kruskal and Wallis and Friedman tests. The initial processing of data, as well as the modelling were performed using Microsoft Excel 2013 ${ }^{\circledR}$ (for further details, see reference [19]). Statistical analyses were performed using Statgraphics Centurion version 2.16.04 (StatPoint Technologies, USA).

\section{Results and discussion}

\subsection{Acidifier behavior of gypsum at pilot scale}

As can be seen from the results in Table 1, the addition of gypsum reduces the $\mathrm{pH}$ of the must before fermentation by a magnitude that is directly related to the dose, which for $3 \mathrm{~g} / \mathrm{L}$ is 0.12 units/g on average. The total acidity does not increase because new $\mathrm{H}^{+}$ions are not created and the tartaric acid concentration and buffering power decrease due to $\mathrm{CaT}$ precipitation. The calcium concentration increases markedly due to the addition of $\mathrm{CaSO}_{4} \cdot 2 \mathrm{H}_{2} \mathrm{O}$ and the potassium concentration does not change. After fermentation, a significant KHT precipitation had occurred due to the formation of ethanol, as shown by the decreases in tartaric acid and potassium concentrations. These decreases are directly related to initial $\mathrm{pH}$ due to the relationship between $\% \mathrm{TH}^{-}$and $\mathrm{pH}$. However, it is necessary to take in account the fact that the $\mathrm{pH}$ would decrease or increase depending on whether this $\mathrm{pH}$ is lower or high than the $\mathrm{pH}$ at which the $\mathrm{TH}^{-}$ion reaches its maximum concentration (see Fig. 1). At the same time, the reduction in $\mathrm{pH}$ and increase in total acidity observed can be justified by the fact that the formation of new acids during fermentation [20] is greater than the reduction produced by KHT precipitation. Two months after fermentation an additional KHT precipitation led to increases in $\mathrm{pH}$ values and reductions in total acidity, both by a magnitude that is in relation

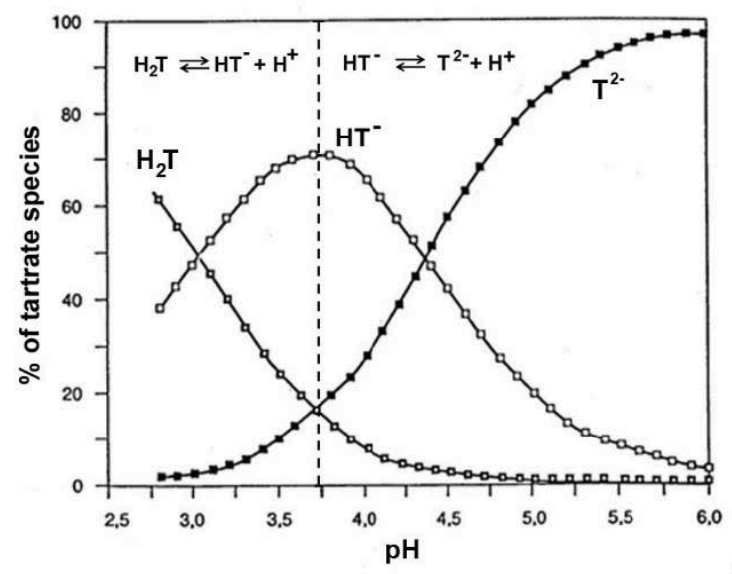

Figure 1. Variation with $\mathrm{pH}$ of $\mathrm{H}_{2} \mathrm{~T}, \mathrm{HT}^{-}$and $\mathrm{T}^{2-}$ concentrations in wine. 


\begin{tabular}{|c|c|c|c|c|c|c|c|c|c|c|c|c|c|c|c|}
\hline 迹 & $\stackrel{9}{0}$ & ñ & $\underline{n}$ & $\mid \begin{array}{c}0 \\
0 \\
0\end{array}$ & $\begin{array}{l}\tilde{b} \\
\stackrel{i}{i}\end{array}$ & $\begin{array}{l}\infty \\
0 \\
0\end{array}$ &  & $\begin{array}{l}\hat{B} \\
i \\
i\end{array} \mid$ & $\stackrel{\sim}{n}$ & $\begin{array}{l}\stackrel{\bullet}{+} \\
+\end{array}$ & $\frac{9}{0}$ & 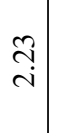 & 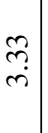 & $\bar{\sigma}$ & 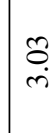 \\
\hline$\frac{\frac{\pi}{2}}{\frac{\pi}{\pi}} \frac{n}{2}$ & $\stackrel{શ}{\dot{r}}$ & $\underset{\sim}{\stackrel{8}{0}}$ & $\begin{array}{l}\vec{F} \\
\dot{r}\end{array}$ & 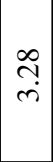 & $\stackrel{\curvearrowleft}{m}$ & 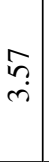 & $\begin{array}{c}0 \\
m \\
m \\
m\end{array}$ & $\begin{array}{l}\tilde{N} \\
\text { r. }\end{array}$ & $\underset{m}{\stackrel{\sim}{m}}$ & $\underset{\dot{m}}{\stackrel{8}{0}}$ & $\begin{array}{l}\vec{b} \\
\dot{r}\end{array}$ & $\stackrel{f}{r}$ & $\begin{array}{l}\stackrel{\sim}{n} \\
\dot{n}\end{array}$ & $\stackrel{\check{c}}{m}$ & $\underset{\sim}{\stackrel{8}{i}}$ \\
\hline$\frac{1}{2}$ & $\underset{\dot{\sigma}}{\dot{+}}$ & $\tilde{\sigma}$ & \begin{tabular}{l|}
$\infty$ \\
$\infty$ \\
$\dot{r}$
\end{tabular} & 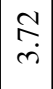 & $\begin{array}{l}P \\
\dot{r}\end{array}$ & 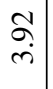 & $\begin{array}{l}\tilde{D} \\
\dot{n} \\
\dot{n}\end{array}$ & $\begin{array}{l}n \\
m \\
m\end{array}$ & $\begin{array}{l}\tilde{b} \\
\dot{n}\end{array}$ & $\begin{array}{l}\vec{b} \\
\dot{r}\end{array}$ & $\begin{array}{l}\stackrel{0}{+} \\
\dot{+}\end{array}$ & $\stackrel{n}{\check{r}}$ & $\begin{array}{l}\hat{\infty} \\
\dot{n}\end{array}$ & $\underset{\sim}{\stackrel{N}{r}}$ & ț \\
\hline$\frac{\overparen{S}}{\&}$ & 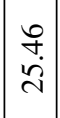 & $\begin{array}{l}\infty \\
\stackrel{n}{n} \\
\sim\end{array}$ & $\begin{array}{l}\overrightarrow{0} \\
\dot{i} \\
\end{array}$ & $\begin{array}{l}\tilde{f} \\
\dot{i} \\
\tilde{n}\end{array}$ & $\begin{array}{l}0 \\
2 \\
\dot{w} \\
m\end{array}$ & $\begin{array}{c}\stackrel{2}{\mathrm{i}} \\
\overrightarrow{\mathrm{i}}\end{array}$ & $\begin{array}{l}\infty \\
\stackrel{\infty}{i} \\
\dot{d}\end{array}$ & $\overrightarrow{\tilde{\lambda}}$ & 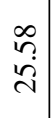 & $\begin{array}{l}\hat{i} \\
\dot{i} \\
\dot{i}\end{array}$ & 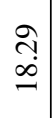 & $\begin{array}{l}\mathcal{f} \\
\infty \\
\infty \\
-\end{array}$ & 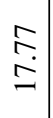 & $\begin{array}{l}\stackrel{2}{8} \\
\dot{i}\end{array}$ & $\begin{array}{l}\text { ते } \\
\text { ते }\end{array}$ \\
\hline$\leq 8$ & $\begin{array}{l}\hat{\sigma} \\
\dot{o} \\
\dot{\sigma}\end{array}$ & 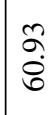 & $\mid \begin{array}{l}\hat{\alpha} \\
\hat{i} \\
\hat{i}\end{array}$ & $\begin{array}{c}8 \\
\dot{\infty} \\
\infty\end{array}$ & $\mid \begin{array}{c}8 \\
\text { id } \\
0\end{array}$ & $\begin{array}{l}r \\
\infty \\
\dot{g} \\
\dot{q}\end{array}$ & $\begin{array}{l}\hat{b} \\
\dot{b} \\
i\end{array}$ & $\frac{9}{\dot{d}}$ & f. & $\begin{array}{l}m \\
\ddot{\infty}\end{array}$ & $\begin{array}{c}\hat{f} \\
\dot{f}\end{array}$ & î̀ & 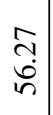 & 盗 & $c$ \\
\hline
\end{tabular}

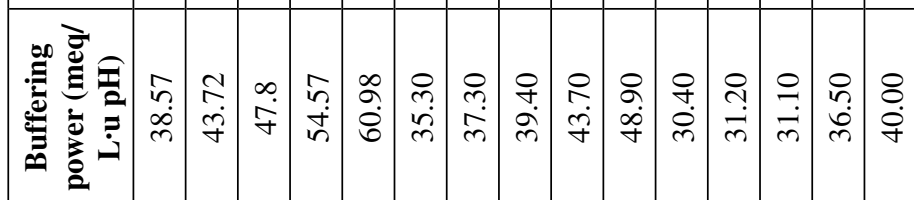

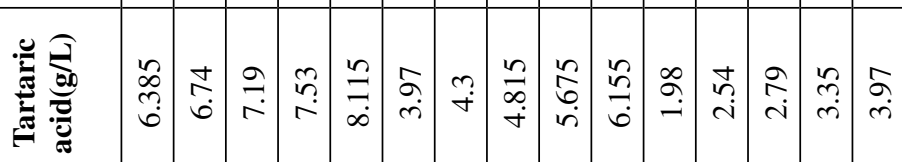

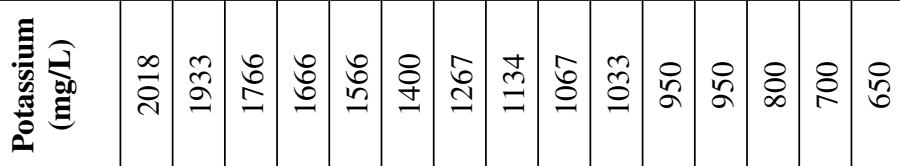



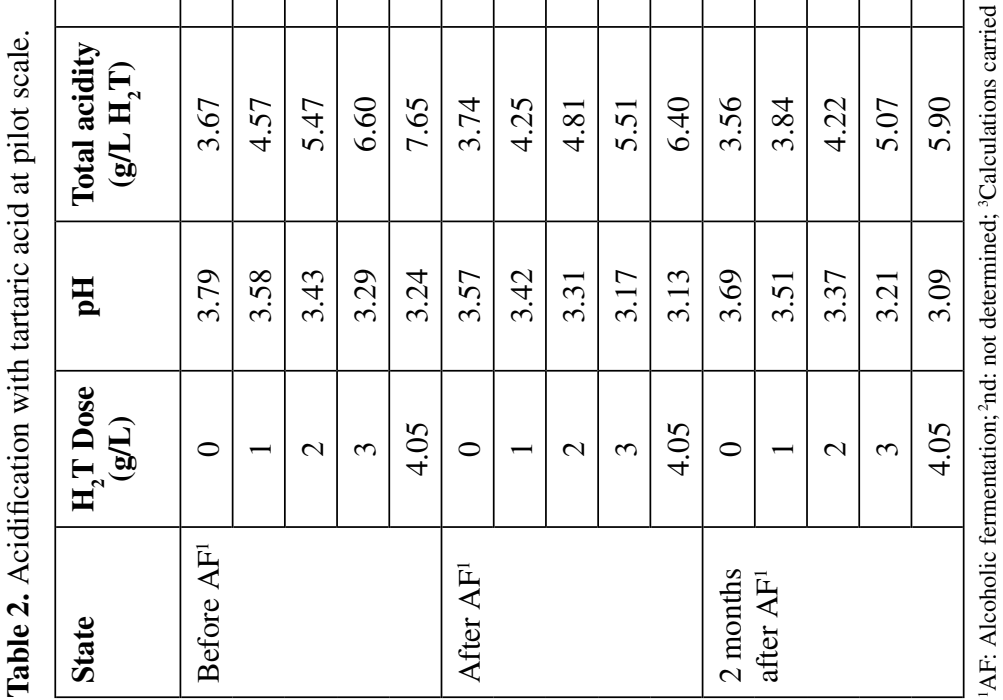


to the initial $\mathrm{pH}$. Finally, calcium concentrations dropped from high initial values of around $200 \mathrm{mg} / \mathrm{L}$ to more suitable final values of around $100 \mathrm{mg} / \mathrm{L}$.

As far as $\mathrm{pH}$ modeling is concerned, the addition of gypsum leads to decreases in AA and TA due to precipitation of $\mathrm{CaT}$ and the considerations: $\mathrm{AA}_{\mathrm{f}}=\mathrm{AA}_{\mathrm{i}}-Y$ and $\mathrm{TA}_{\mathrm{f}}=\mathrm{TA}_{\mathrm{i}}-Y$, were taken into account. Therefore, the chemical model used to predict the $\mathrm{pH}$ values for the addition of gypsum alone [14] is

$$
p H=p K_{V}+\log \frac{A A_{f}}{T A_{f}}=p K_{V}+\log \frac{A A_{i}-Y}{T A_{i}-Y}
$$

where $Y$ is the dose of $\mathrm{CaSO}_{4}$ in meq/L.

As can be seen from the results in Table 1, this model provides a very good prediction of experimental $\mathrm{pH}$ values during all of the studied fermentation steps. The fitting is very good and the relative errors are below $2 \%$. Hence, in this case, the theory is in good agreement with pilot scale experimental results.

\subsection{Acidifier behavior of tartaric acid at pilot scale}

The addition of tartaric acid also reduces the $\mathrm{pH}$ of must in relation to the dose. For a dose of $3 \mathrm{~g} / \mathrm{L}$ the $\mathrm{pH}$ is reduced by 0.17 units/g on average with consequent increases in total acidity and buffering power (Table 2). The tartaric acid concentrations do not increase at the same rate as a result of KHT precipitation induced by the addition of $\mathrm{H}_{2} \mathrm{~T}$. After fermentation, a significant KHT precipitation occurs and this leads to a reduction in the total acidity of wines by a magnitude that is related to the dose of $\mathrm{H}_{2} \mathrm{~T}$ used, despite the formation of new acids. Two months later, KHT precipitation continues and there is a consequent increase in $\mathrm{pH}$ and reductions in total acidity, tartaric acid, potassium concentrations and buffering power.

With respect to the $\mathrm{pH}$ modeling, Eq. (18) is employed in this case. TA, AA and $\mathrm{pKv}$ were calculated in a similar way to the previous case. As discussed above, this model takes into consideration acidification plus precipitation of bitartrate; hence, these assumptions can be translated into the model in the following terms: a decrease in AA and an increase in TA, according to the amount of tartaric acid added $(\mathrm{X}$ meq/L). Equation employed is:

$$
p H=p K_{V}+\log \frac{A A_{f}}{T A_{f}}=p K_{V}+\log \frac{A A_{i}-X}{T A_{i}+X}
$$

where $X$ is the dose of tartaric acid in meq/L [13].

As can be seen from the results in Table 2, good agreement is again observed between experimental and calculated $\mathrm{pH}$ values. In general, the relative errors are very low (less than 3\%) and this can be considered to be a very good result.

\subsection{Acidifier behavior of mixed gypsum and tartaric acid at pilot scale}

The fact that all final $\mathrm{pH}$ values before fermentation are the same for all samples means that changes in all of the parameters depend on the doses of gypsum and tartaric acid used in each case (Table 3). After fermentation, the $\mathrm{pH}$ values were the same in all wines and this finding can be explained because the addition of gypsum reduces the buffering power, which leads to a variation in $\mathrm{pH}$ and compensates for the KHT precipitation. In contrast to the situation described in previous sections, the $\mathrm{pH}$ continues to decrease two months later because the low $\mathrm{pH}$ values are close to the pKa1 of tartaric acid (3.01) and this increases the evolution of the $\mathrm{pH}$ values. In any case, this fact favors the acidifying effect of gypsum.

The chemical models that have appeared in the literature to date [14] are very useful to predict $\mathrm{pH}$ values at different stages of the fermentation process of musts and wines at pilot scale in cases where only one acidifier is used. However, the simultaneous addition of two acidifiers in combination leads to a different situation that is certainly more complex to model.

In our case, different doses of gypsum were added and tartaric acid was added to provide a decrease in $\mathrm{pH}$ to approximately 3.25 . Hence, it can be seen from the results in Table 3 that the higher the amount of gypsum present, the lower the amount of tartaric acid, and vice versa. The model was built in a similar way to those in the two previous cases. The parameters employed were TA, AA and $\mathrm{pK}_{\mathrm{v}}$, which are based on the analytical measurements. According to the results in Table 3, TA and AA decrease in all cases, but at a higher rate prior to fermentation, while $\mathrm{pK}_{\mathrm{v}}$ remains almost constant. The chemical model employed is shown in Eq. (19) [19]:

$$
p H=p K_{V}+\log \frac{A A_{f}}{T A_{f}}=p K_{V}+\log \frac{A A_{i}+Y-X}{T A_{i}+X}
$$

With respect to the model, it should be noted that this is not a direct combination of Eqs. (17) and (18), as one might expect, and the changes mainly concern the denominator, where the contribution of $Y \mathrm{meq} / \mathrm{L}$ of gypsum has been removed. Considering the numerator, the simple combination gives rise to some trends in the relative error values obtained that are not mathematically acceptable and also lead to some infinite errors (negative value) due to the nature of the data. For these reasons, some empirical changes (mathematical signs) were included in the final model (Eq. (19)) in order to avoid these problems. With respect to the denominator, and according to the experimental data (see Table 3), the contribution of gypsum to total acidity is almost negligible, as this factor is principally due to the addition of tartaric acid $\left(\mathrm{TA}_{\text {sample }} \approx \mathrm{TA}_{\text {blank }}+\mathrm{H}_{2} \mathrm{~T}\right.$ dose, in $\mathrm{g} / \mathrm{L}$ ). It can be concluded from the results obtained with Eq. (19) that, in general, the relative errors are rather good, i.e., below $6 \%$, with only two main exceptions for the highest doses of tartaric acid; this fact can be justified because the $\mathrm{pH}$ values are very close to $\mathrm{pK}_{\mathrm{al}}$, which could be considered as a critical point in the acid dissociation equilibria (Fig. 1). Therefore, the model presented here, despite its simplicity, seems to be of great interest for the prediction and control of $\mathrm{pH}$ after combining the addition of gypsum and tartaric acid at pilot scale, regardless of the fermentation stage.

It would be possible to enhance the model but this would certainly involve a more complex and/or more empirical approach, such as a probabilistic one [21]. 


\begin{tabular}{|c|c|c|c|c|c|c|c|c|c|c|c|c|c|}
\hline \multicolumn{2}{|l|}{ 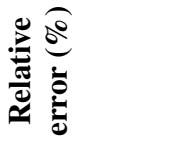 } & $\stackrel{0}{0}$ & 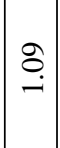 & $\stackrel{5}{0}$ & 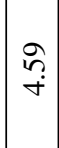 & $\stackrel{\infty}{0}$ & $\stackrel{\Re}{\stackrel{?}{r}}$ & $\stackrel{\Omega}{-}$ & $\stackrel{\hat{r}}{\dot{m}}$ & $\stackrel{7}{0}$ & \begin{tabular}{l|l}
$\infty$ & \\
$\infty$ & $i$ \\
& $i$
\end{tabular} & \begin{tabular}{l|l}
$\vec{i}$ & $\vec{i}$
\end{tabular} & $\overline{\tilde{\sigma}}$ \\
\hline \multicolumn{2}{|l|}{ 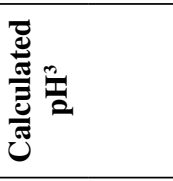 } & $\stackrel{\curvearrowright}{i}$ & $\overrightarrow{\vec{r}}$ & $\begin{array}{l}\text { ஸे } \\
\text { r }\end{array}$ & ले & $\hat{n}$ & $\begin{array}{l}\infty \\
\infty \\
i\end{array}$ & \begin{tabular}{|l|}
$\infty$ \\
0 \\
$\dot{r}$
\end{tabular} & $\begin{array}{l}\varkappa \\
\tilde{c} \\
\tilde{c}\end{array}$ & $\mid \begin{array}{l}a \\
\dot{r}\end{array}$ & 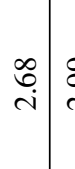 & \begin{tabular}{l|l} 
¿े \\
\end{tabular} & $\begin{array}{l}\text { ते } \\
\text { r. }\end{array}$ \\
\hline \multicolumn{2}{|l|}{$\frac{\vec{a}}{2}$} & $\begin{array}{l}\hat{0} \\
\dot{+}\end{array}$ & $\vec{r}$ & $\begin{array}{l}\infty \\
0 \\
\dot{m}\end{array}$ & $\begin{array}{l}\hat{\sigma} \\
\dot{r}\end{array}$ & $\tilde{\sigma}$ & $\begin{array}{l}\vec{\sigma} \\
\dot{r}\end{array}$ & $\begin{array}{l}3 \\
\dot{r} \\
\end{array}$ & $\begin{array}{l}\hat{b} \\
\dot{r}\end{array}$ & $\begin{array}{l}\stackrel{O}{+} \\
\dot{+}\end{array}$ & 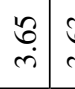 & \begin{tabular}{c|c}
$\hat{B}$ & \\
$\dot{r}$ &
\end{tabular} & $\begin{array}{l}\text { ț. } \\
\dot{r}\end{array}$ \\
\hline \multicolumn{2}{|l|}{$\frac{\widehat{S}}{4}$} & $\begin{array}{l}0 \\
+ \\
i \\
\end{array}$ & $\frac{q}{\dot{m}}$ & $\mid \begin{array}{l}\infty \\
\stackrel{\infty}{\infty} \\
\infty \\
\sim\end{array}$ & $\begin{array}{l}\stackrel{\text { Tे }}{+} \\
\stackrel{\sim}{*}\end{array}$ & $\stackrel{m}{\stackrel{n}{\Delta}}$ & 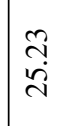 & \begin{tabular}{l|}
$\stackrel{n}{+}$ \\
$\dot{d}$ \\
\end{tabular} & $\begin{array}{l}8 \\
\dot{8} \\
\dot{i}\end{array}$ & 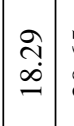 & $\begin{array}{l}n \\
\vdots \\
\grave{2}\end{array}$ & 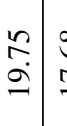 & 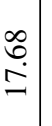 \\
\hline \multicolumn{2}{|l|}{ 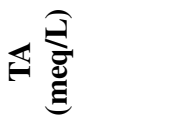 } & $\begin{array}{c}\hat{\alpha} \\
\infty \\
\alpha\end{array}$ & $\begin{array}{l}\hat{\alpha} \\
\dot{\alpha}\end{array}$ & $\begin{array}{l}\hat{\alpha} \\
\infty \\
\infty\end{array}$ & $\begin{array}{l}\hat{\gamma} \\
\dot{\theta}\end{array}$ & $\begin{array}{l}\tilde{\infty} \\
\dot{\sigma} \\
\dot{q}\end{array}$ & $\begin{array}{l}8 \\
\dot{0} \\
\propto\end{array}$ & $\begin{array}{l}5 \\
\dot{0} \\
0\end{array}$ & $\begin{array}{c}\stackrel{\infty}{\infty} \\
\dot{r} \\
\end{array}$ & $\mid \begin{array}{c}\tilde{f} \\
\dot{f}\end{array}$ & 8 & \begin{tabular}{l|l} 
\\
$\stackrel{2}{2}$
\end{tabular} & $\begin{array}{l}\infty \\
\infty \\
\dot{b}\end{array}$ \\
\hline \multicolumn{2}{|c|}{ 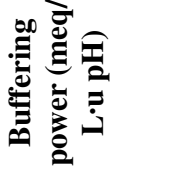 } & $\begin{array}{l}n \\
n \\
\infty \\
\infty\end{array}$ & $\begin{array}{l}n \\
\dot{n} \\
n\end{array}$ & 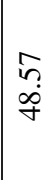 & $\vec{r}$ & $\begin{array}{l}\infty \\
\ddot{n} \\
\ddot{n}\end{array}$ & $\begin{array}{l}\not \\
\dot{\gamma}\end{array}$ & $\begin{array}{c}0 \\
\tilde{i} \\
\tilde{f} \\
\end{array}$ & $\begin{array}{l}8 \\
\dot{\leftrightarrow} \\
\dot{m}\end{array}$ & $\begin{array}{l}q \\
\dot{p} \\
\dot{\rho}\end{array}$ & $\begin{array}{l}q \\
\stackrel{9}{m}\end{array}$ & \begin{tabular}{l|l}
$n$ \\
$n$ \\
$m$ &
\end{tabular} & $\begin{array}{l}\stackrel{0}{1} \\
\text { ri }\end{array}$ \\
\hline \multicolumn{2}{|l|}{ 产 } & $\begin{array}{l}n \\
\infty \\
0 \\
0 \\
0\end{array}$ & $\left|\begin{array}{l}1 \\
0 \\
\infty \\
\infty\end{array}\right|$ & $\stackrel{\infty}{\sim}$ & $\frac{9}{6}$ & $\hat{\grave{m}}$ & $\begin{array}{l}8 \\
\dot{R} \\
\dot{n}\end{array}$ & 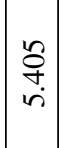 & $\begin{array}{l}\tilde{w} \\
\infty \\
\dot{+} \\
\end{array}$ & $\stackrel{\infty}{\stackrel{9}{-}}$ & సે & 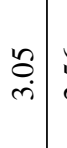 & $\begin{array}{l}\text { in } \\
i \\
i\end{array}$ \\
\hline \multicolumn{2}{|l|}{ 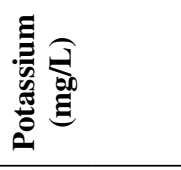 } & $\stackrel{\infty}{\stackrel{\sim}{\vec{\nu}}}$ & $\stackrel{\varrho}{\Xi}$ & ఫ్రి & సิ & 字 & $\stackrel{ \pm}{\Xi}$ & 㝘 & $\begin{array}{c}8 \\
\infty \\
-\end{array}$ & 足 & $\begin{array}{ll}8 \\
\infty \\
\infty\end{array}$ & : & ڤ̊ \\
\hline \multicolumn{2}{|l|}{ 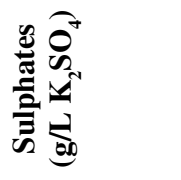 } & $\Xi$ & $\vec{Z}$ & $\vec{\Xi}$ & $\bar{Z}$ & $\stackrel{n}{a}$ & 吕 & 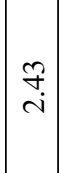 & 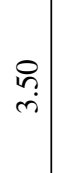 & : & $\stackrel{\overbrace{}}{-}$ & ले & ત્તિ \\
\hline \multicolumn{2}{|l|}{ 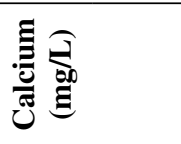 } & $\stackrel{\cong}{\cong}$ & 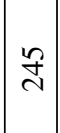 & $\stackrel{?}{\text { ง }}$ & $\stackrel{\overbrace{}}{7}$ & q & $\stackrel{8}{2}$ & \& & 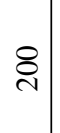 & $q$ & $\cong$ & $\cong$ & $\Xi$ \\
\hline \multicolumn{2}{|l|}{ 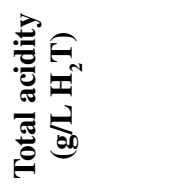 } & $\begin{array}{l}\tilde{6} \\
\dot{m}\end{array}$ & $\mid \begin{array}{l}1 \\
0 \\
0 \\
0\end{array}$ & $\tilde{\sigma}$ & $\begin{array}{l}\widehat{\infty} \\
+ \\
+\end{array}$ & 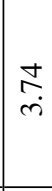 & $\begin{array}{c}n \\
\infty \\
n \\
n\end{array}$ & $\begin{array}{l}n \\
\stackrel{n}{n} \\
\dot{n}\end{array}$ & $\begin{array}{c}\hat{m} \\
\dot{n}\end{array}$ & $\mid \begin{array}{l}0 \\
\\
\end{array}$ & $\begin{array}{l}P \\
i \\
i\end{array}$ & $\begin{array}{l}\text { ㄱ. } \\
\text { in }\end{array}$ & $\begin{array}{l}+ \\
\stackrel{+}{+}\end{array}$ \\
\hline \multicolumn{2}{|l|}{$\frac{\pi}{2}$} & $\stackrel{2}{i}$ & $\mid \begin{array}{c}n \\
\grave{n} \\
\end{array}$ & $\underset{\sim}{\stackrel{d}{n}}$ & ָ̇ & in & $\frac{\sim}{m}$ & $\frac{m}{m}$ & $\frac{m}{m}$ & \begin{tabular}{|l|}
$\hat{a}$ \\
$\dot{c}$
\end{tabular} & \begin{tabular}{l|l}
$\infty$ & \\
$\stackrel{\infty}{r}$ & \\
\end{tabular} & \begin{tabular}{|l|l} 
& \\
0 \\
$\dot{m}$
\end{tabular} & $\begin{array}{l}\hat{0} \\
\dot{m}\end{array}$ \\
\hline \multicolumn{2}{|l|}{ 总 } & 0 & $\begin{array}{l}\tilde{N} \\
\end{array}$ & 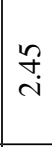 & $\stackrel{9}{2}$ & 0 & $\begin{array}{l}\tilde{N} \\
\ddot{n}\end{array}$ & $\begin{array}{l}q \\
i \\
i\end{array}$ & $\stackrel{?}{-}$ & 0 & \begin{tabular}{l|l}
$\tilde{N}$ \\
\end{tabular} & $\begin{array}{l}\text { fof } \\
\text { in }\end{array}$ & $\stackrel{?}{-}$ \\
\hline \multirow{2}{*}{ 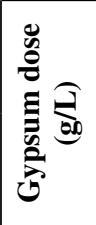 } & $\begin{array}{l}0^{+} \\
\text {స్ } \\
\tilde{U} \\
\end{array}$ & $\begin{array}{l}8 \\
0 \\
0\end{array}$ & $\begin{array}{l}\hat{\imath} \\
0 \\
\end{array}$ & $\stackrel{\infty}{n}$ & $\hat{\tilde{i}}$ & $\stackrel{0}{0}$ & $\stackrel{\hat{\imath}}{\dot{0}}$ & $\stackrel{\infty}{\sim}$ & $\hat{\vec{n}}$ & $\begin{array}{l}8 \\
0 \\
0\end{array}$ & $\stackrel{\overbrace{}}{0}$ & $\stackrel{\infty}{\sim}$ &  \\
\hline & 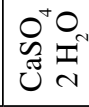 & $\begin{array}{l}8 \\
0 \\
0\end{array}$ & 8 & $\begin{array}{l}8 \\
i\end{array}$ & $\begin{array}{l}8 \\
\dot{m}\end{array}$ & 8 & $\stackrel{8}{-}$ & $\begin{array}{l}8 \\
i \\
i\end{array}$ & $\begin{array}{l}8 \\
\dot{r}\end{array}$ & $\begin{array}{l}8 \\
0 \\
0\end{array}$ & $\underset{-}{8}$ & $\begin{array}{l}8 \\
i\end{array}$ & $\begin{array}{l}8 \\
\dot{r}\end{array}$ \\
\hline \multicolumn{2}{|l|}{ 苟 } & \multicolumn{4}{|c|}{ 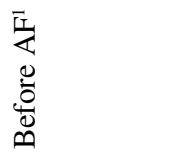 } & & \multicolumn{4}{|c|}{ 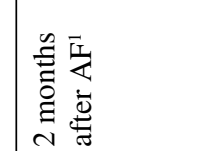 } \\
\hline
\end{tabular}




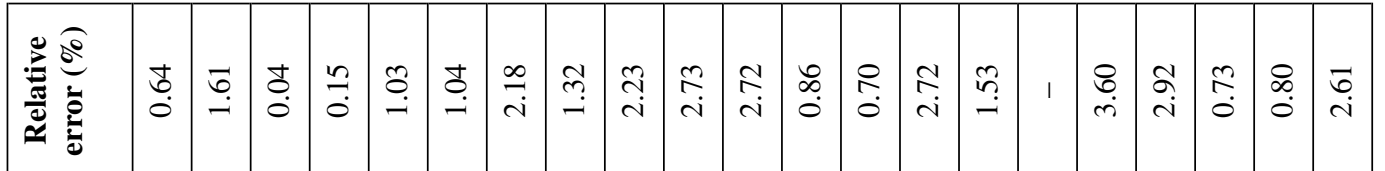

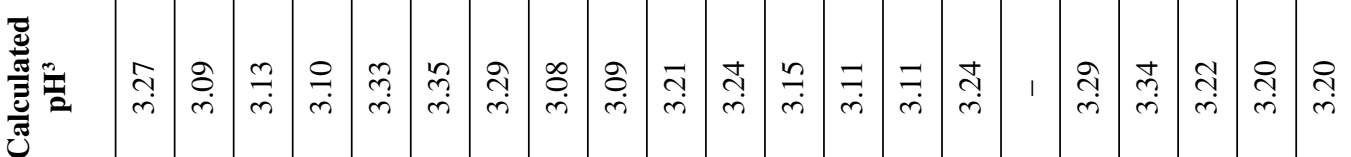

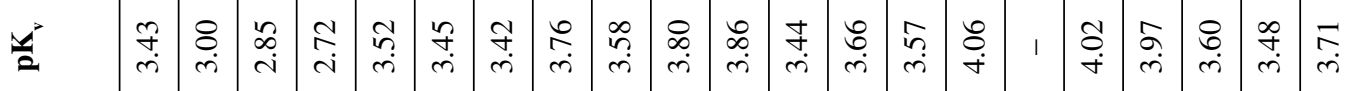

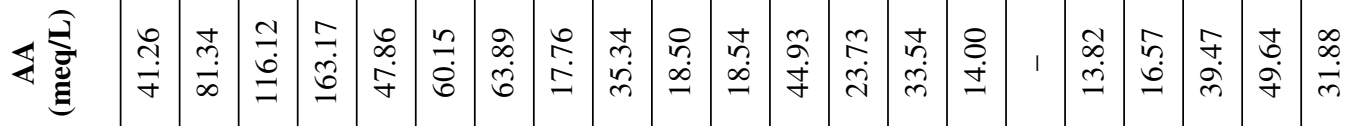

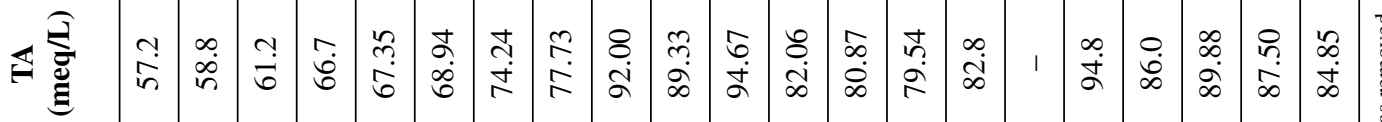

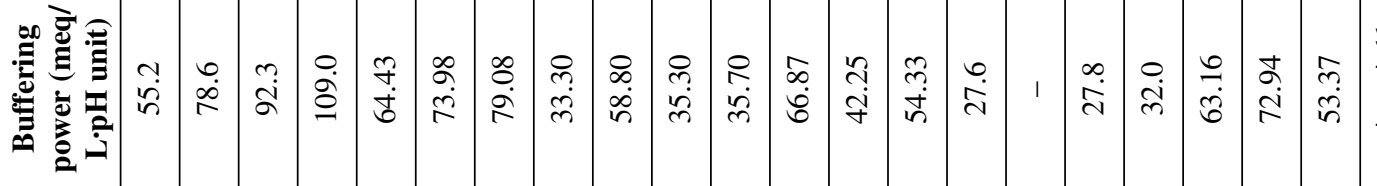

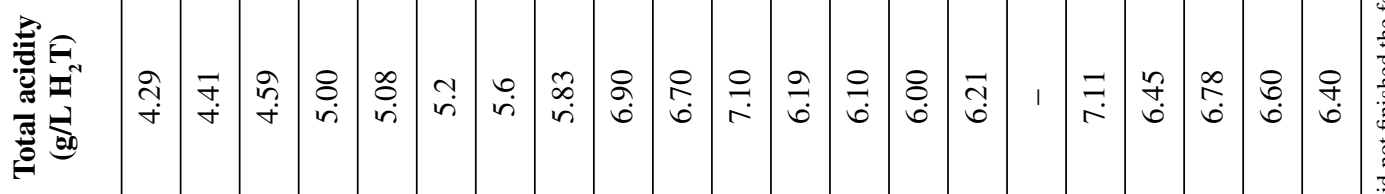

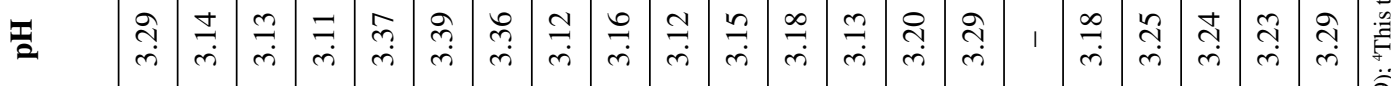

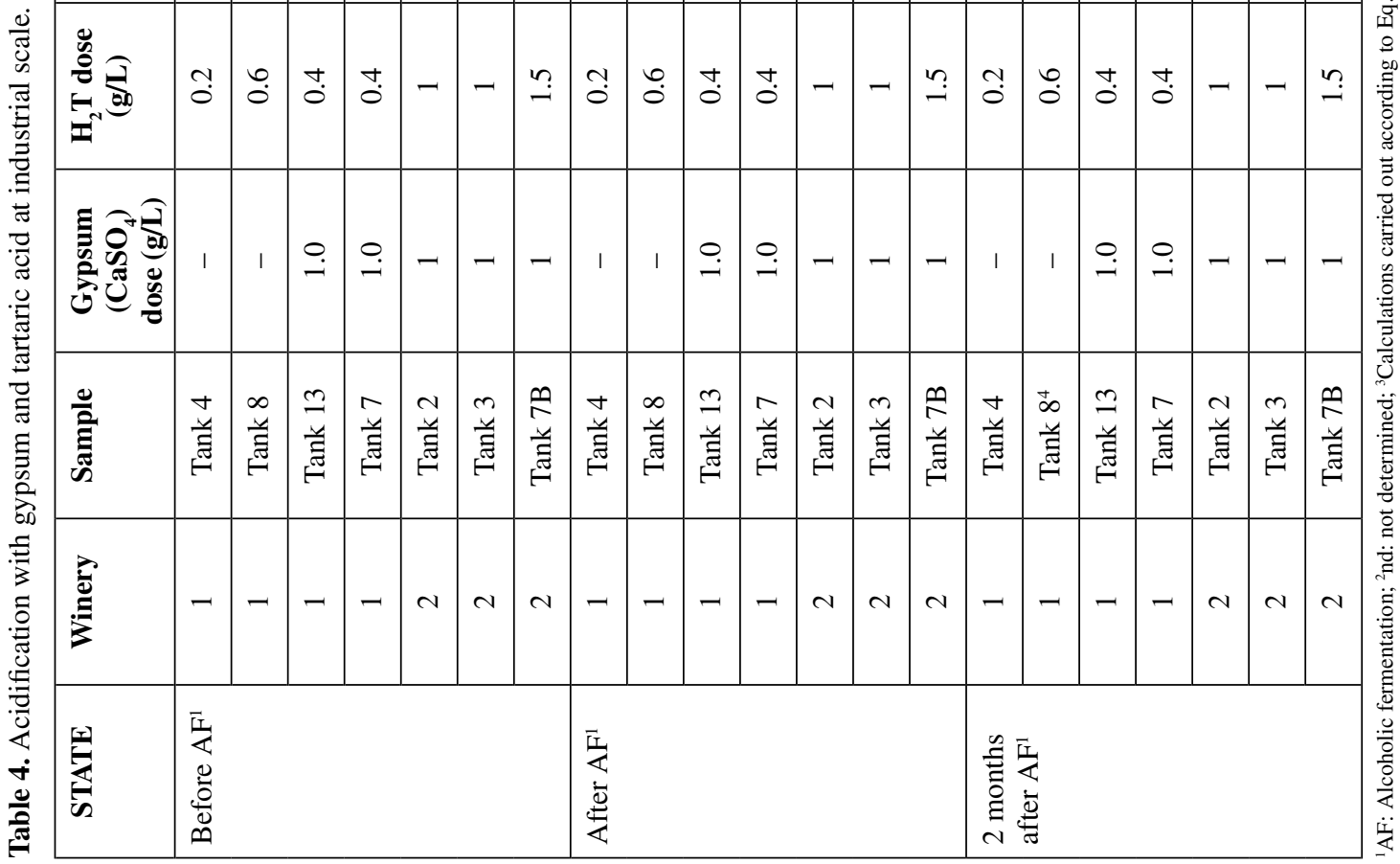


Table 5. Anova table of the acid scores of the acidified wines.

\begin{tabular}{|l|c|c|c|c|c|}
\hline Sourceof Variance & Sum of Squares & Df & Mean Square & F-Ratio & P-Value \\
\hline Between-groups & 14.75 & 4 & 3.6875 & 2.08 & 0.1132 \\
\hline Within-groups & 44.25 & 25 & 1.77 & & \\
\hline Total (Corr.) & 59.0 & 29 & & & \\
\hline
\end{tabular}

\subsection{Acidifier behavior of gypsum and tartaric acid at industrial scale}

The study at industrial scale was carried out in two different wineries in the harvest of 2014. In Winery 1, acidifications with only tartaric acid and with the mixture of gypsum and tartaric acid were used, and on the contrary, in Winery 2 all the musts were acidified with gypsum and tartaric acid.

Some analytical parameters measured, along with the calculated $\mathrm{pH}$ values and relative errors obtained, are collected in Table 4. The models employed were those mentioned in the previous cases, without modification. As can be seen from the results shown in both tables, the errors in $\mathrm{pH}$ predictions were less than $3.9 \%$, what implies an excellent performance of the model, despite the difficulties of applying the described methodology for industrial scale: It is obvious that the control of the behavior of chemical equilibria on an industrial scale is definitively more complicated than on a pilot scale, mainly due to the difference in volume ( 25 vs. $30,000 \mathrm{~L}$ ) and the difficulty in achieving complete homogenization of the media after adding gypsum, tartaric acid or both. These facts make the results noteworthy.

\subsection{Sensorial analysis}

The ANOVA table (Table 5) decomposes the variance of the data into two components: a between-group component and a within-group component. The F-ratio, in this case equal to 2.08, corresponds to the between-group estimate/the within-group estimate ratio. Since the $p$-value of the F-test is greater than or equal to 0.05 , statistically there is no significant difference between the acid scores of the samples at the $95.0 \%$ confidence level. In other words, the acidification process based on a mixture of gypsum and tartaric acid implies no significant difference in the final product in terms of acid taste with respect to other wines treated with common and usual acidification processes.

\section{Conclusion}

Considering some discrete aspects of acidification with gypsum or tartaric acid, it has been verified that the addition of gypsum leads to a reduction in $\mathrm{pH}$ of $0.12 \mathrm{pH}$ units/ $\mathrm{g} / \mathrm{L}$ without an increase in total acidity and a reduction in the buffering power. Moreover, the addition of tartaric acid reduces the $\mathrm{pH}$ by $0.17 \mathrm{pH}$ units/g/L with marked increases in total acidity and buffering power. The addition of gypsum initially produces a significant increase in sulfate and calcium concentrations, although calcium decreases appreciably in the first two months. The addition of tartaric acid leads to a marked reduction in potassium concentrations because of the induced precipitation of KHT. And considering the global acidification processes, the combined addition of gypsum and tartaric acid produces an additive effect when compared to the doses of each one individually and this allows a reduction in the doses of tartaric acid necessary to achieve a $\mathrm{pH}$ of enological interest. Consequently, it has been verified that in warm regions it is possible to use both acidifiers in combination to reduce $\mathrm{pH}$ accurately. Lower amounts of tartaric acid can be used and the levels required are closer to the legal limits. Chemical modeling in which tartaric acid is considered to be monoprotic has shown excellent $\mathrm{pH}$ predictions for the effects of gypsum and tartaric acid in almost all cases. Finally, it has been verified that there is no significant differences in terms of acid taste among wines acidified with different acidifiers. In consequence, it can be concluded that the use of gypsum is still of great interest for must acidification in warm regions, and its use should be approved by the OIV.

\section{References}

[1] R.A. Plane, L.R. Mattick, L.D. Weirs, Am. J. Enol. Vitic. 31 (3) 265-268 (1980).

[2] J.M Harris, P.E. Kriedermann, J.V. Possingham, Vitis 9 291-298 (1971).

[3] European Community. Council Regulation (EC) $N^{o}$ $479 / 2008$ on the common organisation of the market in wine. Official Journal of the European Union L1481-61 (2008).

[4] European Community. Commission Regulation (EC) $N^{o}$ 606/2009 laying down certain detailed rules for implementing Council Regulation (EC) $N^{o} 479 / 2008$ as regards the categories of grapevine products, oenological practices and the applicable restrictions. Official Journal of the European Union L1531-59 (2009).

[5] e-CFR.Electronic Code of Federal Regulations. (2010). Title 27: Alcohol, Tobacco and Firearms PART 24 WINE Subpart L Storage, Treatment and Finishing of Wine $\S 24.246$ Materials authorized for the treatment of wine and juice. Available on line at http: //www. ecfr.gov/cgi-bin/ text-idx?SID=5a39ba6737562446636a5 b54a87b3961\&node $=27: 1.0 .1 .1 .19 .12 \&$ rgn=div6\#2 $7: 1.0 .1 .1 .19 \cdot 12.343 .7$, last accessed 12 April 2014.

[6] Plinius Maior. (1st Century). Naturalis historiae, Book XIV, Chapter XIX.

[7] G. Fernández de Bobadilla, J.M. Quirós, J.J. Serrano,The plastering of musts. Journal of the National Institute of Agronomic Research (INIA) 31 411-416 (1954). 
[8] M.M. Gonzalez-Gordon. Sherry. The Noble Wine. (1972).

[9] J. Jeffs. Sherry (3rd ed.). London (1982).

[10] M. A. S. Pato. Use of plaster for acidity correction in musts and wines. .De Vinea et vino Portugaliea Documenta, Serie II Enology,, Vol. 5( No $^{\circ}$ ) (1971).

[11] J. Gómez Benítez, M.M. Grandal Delgado, J. Díez Martín,Am. J. Enol. Vitic. 44(4) 400-404 (1993).

[12] J.F. Casas Lucas. The winemaking in Jerez in the $X X$ century. Antecedents, interpretation and contributions 1955-1985. Seville. Spain: Junta de Andalucía. Consejería de Agricultura y Pesca (2008).

[13] R. Boulton Am. J. Enol. Vitic. 31(2) 182-186 (1980).

[14] J. Moreno Vigara, R.A. Peinado Amores. Oenological Chemistry (1 ${ }^{\text {st }}$ ed.). San Diego CA. (USA): Academic Press (2010).

[15] L. Usseglio-Tomasset, Chimica Enologica. Brescia. Italy: Ed. AEB(1995).
[16] European Community. Council Regulation (EEC) $N^{o}$ 2676/90 determining the Community analysis methods applicable in the wine sector.Official Journal of the European Community L2721-192 (1990).

[17] J. Trossais, C. Asselin, Vigne Vin 19 Nº 249-259 (1965).

[18] ISO 8586:2012. Sensory analysis. General guidelines for the selection, training and monitoring of selected assessors and expert sensory assessors

[19] J. Gómez, C. Lasanta, J.M. Palacios-Santander, L.M. Cubillana-Aguilera, Food Chem. 168 218-224 (2015).

[20] Y. Shimazu, M. Watanabe,J.Ferment. Tech. 59(1) 27-32 (1981).

[21] M.E. Sturm, F.N. Arroyo-López, A.GarridoFernández, A. Querol, L.A. Mercado, M.L. Ramirez, Int. J.Food Microbiol. 170 83-90 (2014). 